\title{
EXPLORAÇÃO DA EXPERIÊNCIA HISTÓRICA QUE CONDICIONOU A RECEPÇÃO E O SURGIMENTO DAS IDÉIAS JURÍDICAS NO BRASIL
}

\author{
Jeannette Antonios Maman \\ Professora Doutora do Departamento de Filosofia e Teoria \\ Geral do Direito da Universidade de São Paulo; professora do \\ Centro de História das Ciências da Universidade de São Paulo
}

\section{Resumo:}

Este trabalho relata, através de vários períodos da história do País, o surgimento das ideias jurídicas, que vai desde a chegada dos portugueses, em 1500, mesclada com a dominação dos conquistadores europeus, até os dias de hoje.

Abstract:

This work tells, through the several periods of the history of Brazil, the appearance of the juridical ideas, that it is going from the arrival of the Portugueses, in 1500, blended with the European conquerors' dominance, until nowadays.

Unitermos: períodos da história; surgimento das ideias jurídicas.

Sumário: $1^{0}$. período: colonialismo mercantil escravista; $2^{\circ}$. período: colonialismo mercantil escravista e de povoamento; $3^{\circ}$. período: neocolonialismo; $4^{\circ}$. período: neocolonialismo multinacional

As condições de existência material e espiritual no Brasil foram resultado de uma experiência histórico-cultural, sócio-econômica, política, sensível e mental.

Afasta-se aqui a proposição muito comum que afirma ser a experiência jurídica condicionada por certas idéias, o que nos faria supor a eleição de uma filosofia idealista para analisar o fenômeno jurídico.

Com a chegada dos portugueses ao Brasil, a partir de 1500, houve uma influência cultural dos brancos europeus de várias procedências (com as posteriores incorporações asiáticas), que se mesclou à cultura ameríndia e africana. Compreendida aqui a cultura como um conjunto de crenças, sentimentos coletivos e 
idéias, não podemos dizer que ela esteja desarraigada dos fatos históricos da época o expansionismo colonial e as pretensões econômicas de Portugal (e, no caso, da nossa América, também os espanhóis). De onde decorre que a primeira experiência jurídica brasileira foi de dominação pelos europeus conquistadores até nossos dias. $\mathrm{Na}$ verdade, $\mathrm{o}$ interesse estrangeiro e a sujeição de nossos povos condicionaram a recepção das idéias na América Latina.

A crise do feudalismo na Europa cria, no século $X V$ a necessidade de expansão comercial é preciso que haja mercados produtores de gêneros alimentícios e matéria-prima, e consumidores dos manufaturados europeus (hoje se diz aos nossos povos que é preciso manter a biodiversidade e os Estados Unidos da América querem manter-nos consumidores de seus produtos...).

Portugal foi o país que deu início à expansão marítima, seguido pela Espanha, Holanda, França e Inglaterra. É de absoluta importância fixarmos o fato histórico de que o período de expansão marítima e colonial criou condições para 0 surgimento da Revolução Industrial e, por consequiência, do modo de produção capitalista. Há muitos séculos fazemos a riqueza do primeiro mundo, que hoje mantém os países periféricos como economias complementares, sustentanto um sistema que nos exclui. O Brasil sempre teve função provedora para os europeus, que escravizaram os povos naturais e ainda importaram milhões de africanos na condição servil - todos submetidos às suas leis da força, da técnica e da dominação.

Assim, nossa experiência jurídica não é isolada da experiência histórica nem autônoma, mas ao contrário dependente de ideologias estrangeiras.

Nesse sentido, resume com muita clareza o professor Aloysio Ferraz Pereira, em comunicação inédita, apresentada no II Congresso Brasileiro de Filosofia Jurídica e Social em 1986:

A experiência jurídica fundamental entre as nações latino-americanas, desde quando puderam reconhecerse um mínimo de identidade política, foi a de subordinação da grande maioria não européia ao direito de estados europeus. É certo também que a aplicação desse direito faz parte do processo político geral de espoliação, de culturação e destruição das massas indigenas e africanas, instituído $e$ sistematicamente executado por espanhóis e 
portugueses, em associação posterior com as

oligarquias locais, que mais tarde os sucederam, para

construir-se em uma classe intermediária entre o povo $e$

$o$ estrangeiro, sob o senhorio e no interesse do estrangeiro"

Se num primeiro período da colonização a marca foi a de um mercantilismo-escravista (séculos XVI e XVII), este seria seguido por um período no qual o povoamento se tornaria necessário à expansão capitalista (séculos XVIII e $\mathrm{XIX).} \mathrm{E} \mathrm{o} \mathrm{neo-colonialismo} \mathrm{dos} \mathrm{séculos} \mathrm{XIX} \mathrm{e} \mathrm{XX} \mathrm{garantiria} \mathrm{a} \mathrm{contraparte} \mathrm{dos}$ povos da América Latina, sujeitos ao poder norte-atlântico e sua revolução tecnológica-industrial. Surge uma nova dependência: os países da América Latina participam do mercado mundial como produtores de matérias-primas $\mathrm{e}$ consumidores de parte da produção do antigo sistema colonial e sua independência política seria obra das classes beneficiárias do antigo sistema colonial, que queriam apenas liberdade de comércio. Não se pode dizer, salvo as exceções, que confirmam a afirmação, que tenha havido momentos políticos revolucionários; antes, houve interesse dos grandes proprietários rurais e da burguesia nas facilidades "liberais" que lhes traria a independência.

Os dois primeiros períodos organizaram a vida mercantil das colônias em função do comércio internacional. Até o povoamento obedeceu às facilidades com que, graças ao comércio mundial, se atendia à produção e entrega das matériasprimas, produtos agrícolas e minerais: algodão, arroz, tabaco, açúcar, ouro e diamantes. ${ }^{l}$

1. Furtado, Celso. Formação Econômica do Brasil, Editora Fundo de Cultura, 1961, p. 109. Material necessário de valor documental probatório.

"Os colonos do Maranhão eram adversários tradicionais dos jesuitas na luta pela escravidão dos índios. Pombal ajudou-os criando uma companhia de comércio altamente capitalizada que deveria financiar o desenvolvimento da regiāo, Iradicionalmente a mais pobre do Brasil. Tão importante quanto a ajuda financeira, entretanto, foi a modificação no mercado mundial de produtos tropicais, provocada pela guerra de independência dos Estados Unidos e logo em seguida pela revolução industrial inglesa. Os dirigentes da companhia perceberam desde o início que o algodão era o produto tropical cuja procura estava crescendo com mais intensidade, e que o arroz produzido nas colônias inglesas e principalmente consumido no Sul da Europa não sofria restriçāo de nenhum pacto colonial. Os recursos da companhia foram assim concentrados na produçāo desses dois artigos." A produçāo maranhense encontrou, assim, condições altamente propícias para desenvolver-se e capitalizar-se adequadamente. A pequena colônia, em cujo porto entravam um ou dois navios por ano e cujos habitantes dependiam do trabalho de algum indio ou escravo para sobreviver, conheceu excepcional 
Ainda que se ressaltem, na ocupação européia, os fins salvacionistas, o que moveu os primeiros navegadores foi a busca do ouro. Significativas são as passagens dos diários de Cristovão Colombo (que também deixam claramente a intenção de escravizar os povos naturais). Após o desembarque nas Bahamas (12 de outubro de 1492), na ilha que se chamou de San Salvador, escreve no dia 15:

\begin{abstract}
"... todos esses homens que trago de San Salvador indicam que há verdadeiro esbanjamento de ouro, ostentando-o em feitios de argolas nos braços e nas pernas e nas orelhas, nariz e pescoço. ... e é ouro.... Não posso errar e, com ajuda de Nosso Senhor, hei de encontrá-lo onde nasce. 2
\end{abstract}

Escreveria no dia 16 de dezembro:

"E estes índios são dóceis e bons para receber ordens e fazê-los trabalhar, semear e tudo o mais que for preciso, e para construir povoados e aprender a andar vestidos $e$ a seguir nossos costumes" 3

A colonização imporia a exploração e a escravidão que persistiria como marca ignóbil. ${ }^{4}$

Adotando as categorias antropológicas elaboradas pelo professor Darcy Ribeiro, podemos dividir a história da experiência jurídica brasileira em quatro períodos, concomitantes aos dos povos americanos de colonização espanhola:

prosperidade no fim da época colonial, recebendo em seu ponto de cem a cento e cinqüenta navios por ano e chegando a exportar um milhão de libras.

"Excluídos o núcleo maranhense, todo o resto da economia colonial atravessou uma etapa de séria prostração nos últimos decênios do século."

2. Colombo, Cristovão. Diários da Descoberla da América, Porto Alegre, L\&PM Editores Ltda.. 1984 , p. 49.

3. Idem, Ibidem, p. 74.

4. Schwarz, Roberto. Ao vencedor as batatas, São Paulo, Livraria Duas Cidades Ltda., 1988, p. 14.

"A Declaração dos Direitos do Homem, por exemplo, transcrita em parte na Constituição Brasileira de 1824, não só não escondia nada, como tornaria mais abjeto o instituto da escravidão" 
$\left.1^{\circ}\right)$ período do colonialismo mercantil escravista; correlativo essencial à formação sócio-cultural dos impérios mercantis salvacionistas ibéricos; consecutivos à revolução mercantil, considerada como transformação tecnológica e processo civilizatório: séculos XVI e XVIII.

$\left.2^{\circ}\right)$ periodo do colonialismo mercantil escravista e de povoamento; correlativo necessário à formação sócio-cultural do capitalismo, ainda conseqüente à revolução tecnológica mercantil, mas correspondente ao processo civilizatório da expansão capitalista: séculos XVIII e XIX.

$\left.3^{\circ}\right)$ período do neo-colonialismo; contraparte integrante da formação sócio-cultural do imperialismo industrial, processo civilizatório que se seguiu à revolução tecnológica industrial: séculos XIX e XX.

$\left.4^{\circ}\right)$ período do neo-colonianismo multinacional.

Os povos latino-americanos "sofrem" nesses períodos, um processo civilizatório que, segundo o citado antropólogo, são de atualização histórica, quando os povos subjugados perdem sua autonomia cultural, submetidas que são estas etnias ao poder de dominação e exploração dos povos em expansão.

A atualização histórica opera por meio da dominação e do avassalamento de povos estranhos, seguida da ordenação econômico-social dos núcleos em que se aglutinam os contingentes dominados para efeito de instalar novas formas de produção ou explorar antigas atividades produtivas. Esta ordenação tem como objetivo fundamental vincular os novos núcleos à sociedade em expansão, como parcela do seu sistema produtivo e como objeto de difusão internacional de sua tradição cultural, por meio da atuação de agentes de dominação" 5

5. Ribeiro, Darcy. As Américas e a Civilização, Petrópolis, Editora Vozes Ltda., 1983, p. 36.

Id. p. 35. Material necessário para precisão conceitual.

"A partir do século XVI, se registraram duas revoluçōes tecnológicas responsáveis pelo desencadeamento de quatro processos civilizatórios sucessivos. Primeiro, a Revolução Mercantil que, num impulso inicial de caráter mercantil salvacionista, ativou os povos ibéricos e os russos, lançando aqui conquistas oceânicas e a estes à expansão continental sobre a eurasia. Num segundo impulso, de caráter mais maduramente capitalista, a Revolução Mercantil, depois de romper a estagnação feudal 
Os três períodos de atualização histórica dos povos latino-americanos foram acompanhados por uma experiência jurídica que assim se pode resumir:

$1^{\circ}$ ) período (séculos XVI e XVIII) do colonialismo mercantil escravista

O governo português, no primeiro período de colonização, fez com que as relações no Brasil fossem regidas pelas Ordenações Filipinas (1603), que mantinham fidelidade ao pensamento aristotélico, sem sofrer influência do individualismo voluntarista, mas aplicadas a uma ordem social em transformação, onde se dá o aparecimento da classe burguesa e se implanta um poder soberano, cuja vontade mantinha um "contrato" entre indivíduos pretensamente livres e iguais. A posição de Portugal era singular na Europa: não conhecera o feudalismo de outros países e não conheceria, até o século XVIII, as idéias e instituições individualistas e liberais.

O "Prólogo" ${ }^{16}$ de Felipe II às Ordenações Filipinas ("assim deve fazer o bom Rei, pois por deus foi dado") garantia a ideologia salvacionista, justificada pela origem divina do poder e permitiria, do ponto de vista latino-americano: encobrir ou dissimular, aos olhos próprios e alheios, o infinito cortejo dos crimes e pecados que os europeus cometeram aqui, contra a humanidade e contra o seu Deus" $^{7}$

em certas áreas da Europa, lançou os holandeses ingleses e franceses à expansão colonial no alémmar. Seguiu-se a Revolução Industrial que, a partir do séc. XVIII, entrou a promover uma reordenação do mundo sob a égide das nações pioneiras da industrialização, através de dois processos civilizatórios: a expansão imperialista e a reordenação socialista. Assim é que se modelaram, em conseqüência da expansão mercantil-salvacionista, por aceleração evolutiva, os Impérios Mercantis Salvacionistas e, por atualização histórica, os seus contextos Coloniais Escravistas. Mais tarde, em conseqüência do segundo processo civilizatório, se cristalizaram, por atualização, suas formações Capitalista Mercantis e, por, atualização, suas dependências Coloniais Escravistas, Colonias Mercantis e Coloniais de Povoamento. Finalmente, como fruto do primeiro processo civilizatório provocado pela Revolução Industrial, surgiram, por aceleração, as formações Imperialistas Industriais e, por atualização, sua contraparte Neocolonial".

6. "Prólogo" de Felipe II às Ordenações Filipinas:

"Como a Justiça consiste em igualdade e com justa balança dar o seu a cada um, assim o bom Rei deve ser sempre um, e igual para todos em retribuir e premiar cada um segundo seus merecimentos: $E$ assim como a Justiça é virtude não para si, mas para outrem, por aproveitar somente àqueles a que se faz, dando-se-lhes o seu e fazendo-os bem viver, aos bons com prêmios, e aos maus com temor das penas, donde resulta paz e assossego na República"... Vide nota seguinte.

7. Pereira, Aloysio Ferraz. Comunicação inédita apresentada no II Congresso Brasileiro de Filosofia Jurídica e Social, em 1986. 

jurídicas no Brasil

"Desde os primeiros contatos europeus com os índios, a transição foi rápida, passando do escambo pacífico com os navios à sua escravização pelos invasores, ainda antes do fim do século XVI. O instituto do trabalho escravo, a mita, a encomenda $e$ muitos outros, nominados e inominados, constituem o direito eficaz na América Latina, direito que legitimou os genocídios, o secular processo do saque sistemático, o sacrilégio, o estupro, a destruição bestial da cultura dos povos outros. Tudo isso, à sombra da cruz, sob a égide da civilização greco-latina. É verdade que sempre há de se ouvir a voz de apóstolo de Bartolomé de Las Casas e também o verbo retórico, mas tantas vezes sincero, de Antônio Vieira" 8

$2^{\circ}$ ) período (séculos XVIII e XIX) do colonialismo mercantil escravista e de povoamentos

A agricultura de exportação persiste como forma econômica que se beneficia do tráfico de escravos africanos, mais fortes e melhores para o trabalho do que os índios escravizados. A Holanda também fornece escravos com seus navios mercantes. Portugal intensifica a imigração e o povoamento se dá a fim de explorar as fazendas de gado no Nordeste (onde aumenta o trabalho livre), dedicar-se à monocultura, que provoca crise nos produtos de subsistência. Há núcleos coloniais no sul, no Rio de Janeiro e em São Paulo. A administração no Brasil seria opressiva, com restrições econômicas, que impediam o comércio com outros países que não Portugal (é o chamado "pacto colonial"). Os juízes ordinários, eleitos pelo povo, foram substituídos pelos juízes de fora, nomeados pelo Rei. Concediam-se monopólios a particulares, com o sistema de companhias privilegiadas, como faziam ingleses e holandeses em suas colônias. A função do Brasil-colônia era atuar como agente de acumulação capitalista européia, e sua história de subdesenvolvimento começa com a história da emergência e desenvolvimento do sistema capitalista 
mundial. A América Latina, desde fins do século XVIII, ingressava na órbita da Inglaterra e só sairia para entrar na norte-americana após a Primeira Grande Guerra.

O século XVIII seria marcado especialmente pela exploração do ouro e de diamantes, e toda esta produção, bem como a agrícola e extrativa vegetal abasteceriam o mercado europeu através de Portugal.

O povoamento é distribuído em função dos interesses econômicos europeus: escolhem-se as regiões de agricultura segundo as preferências dos consumidores (áreas próprias para cultura tropical). Os portos e feitorias serão os mais próximos da Europa. A metrópole mantém o monopólio do comércio que se funda em leis e institutos jurídicos importados.

O pensamento jurídico filosófico do século XVII se dividia segundo as tendências portuguesas e espanholas. Se Portugal ainda estava preso ao pensamento greco-romano (Aristóteles, São Tomas de Aquino, o Direito Romano e a Escola de Bolonha), a Espanha sofria a influência do individualismo de Santo Agostinho e do nominalismo de Okham pela mediação da escolástica tardia.

O Marquês de Pombal, em Portugal, representa a modernização iluminista, que se refletia na colonização européia. A obra de Tomás Antonio Gonzaga, Tratado de direito natural, mostraria o ecletismo da ilustração da época.

Mas a opressão administrativa de Portugal gera descontentamento e a Inconfidência Mineira que se fez no cotidiano (no dia a dia das conversas entre descontentes e idealistas, com talvez um único rebelde, José Joaquim da Silva Xavier).

"Desde a repressão exemplar da Inconfidência Mineira pode-se dizer que a grande etnia do Brasil entra em acelerado processo de conscientização social $e$ política, de que participa grande número de portugueses. Para documentar a mudança de consciência de classe dos senhores e mestiços basta comparar o sentido crítico de uma ideologia nativa, que nitidamente reponta em Gregório de Matos, no séc. XVII, com o que se manifesta nas Cartas Chilenas, de Gonzaga, no séc. XVIII. Gregório é uma espécie de franco atirador, avulso e desengajado, que ataca todos os grupos e camadas sociais, sem liames de 
solidariedade política com qualquer das etnias em presença, embora o seu intratável moralismo encontre o seu princípio na religião e na mística. Ao contrário, nos inconfidentes já se definem claramente um ressentimento coletivo, uma unidade das críticas e o mesmo propósito, se não ainda projeto, de modelagem nacional e de bem comum. $^{9}$

$3^{\circ}$ ) período (séculos $\mathrm{XIX}$ e $\mathrm{XX}$ ) do neo-colonialismo

A partir de 1808 , com a chegada da família real portuguesa, a experiência econômica brasileira vai mostrar claramente os efeitos das graves restrições feitas à produção manufatureira do Brasil, desde o início do século XVIII com o Tratado de Methuen, celebrado entre Inglaterra e Portugal, beneficiando os interesses dos produtores ingleses de tecidos de lã. O governo britânico manteve sempre fiscalização atenta a esses acordos restritivos, que beneficiavam 0 imperalismo industrial em sua expansão. A Inglaterra pôde ocupar os mercados latino-americanos, para os quais continuava exportando idéias que convinham ao poder dominante; uma delas (na qual ainda hoje se insiste) afirmava a "vocação natural" destes povos (latinos) para a exportação de matérias-primas e gêneros alimentícios; e que deveriam importar tudo o mais. A produção incipiente de manufaturados nas colônias desaparece sem proteção alfandegária; não se passará, como na Europa, da manufatura à grande indústria; não se criou uma burguesia industrial capaz de construir uma sociedade moderna, baseada no desenvolvimento industrial e no trabalho assalariado.

Se o pacto colonial entre a colônia e a metrópole impediria o progresso industrial, a abertura dos portos, as importações da Grã-Bretanha, da França e de todo o continente europeu acabariam por deixar Portugal e o Brasil dependentes de um capitalismo industrial, que substitui um capitalismo mercantil já decadente. Essa dependência econômica traz uma conseqüência: a subordinação política à Inglaterra e da Espanha à França. 
"O plano inglês de compensar-se de suas derrotas no continente europeu com a conquista das colônias iberoamericanas é óbvio. No caso do Brasil, as circunstâncias favoreceram e facilitaram este plano. Não precisará ai de exércitos e de intervenções armadas, pois o soberano português, temendo a sorte de Fernando VII de Espanha, entendeu mais conveniente aceitar o oferecimento inglês e embarcar sob proteção britânica para o Brasil. Conservava com isto sua coroa e títulos, mas terá cedido ao aliado inglês a sua independência e liberdade de ação. A monarquia portuguesa não será daí por diante mais que um joguete nas mãos da Inglaterra $O$ soberano permanecerá no Rio de Janeiro sob a guarda de uma divisão naval inglesa, ai estacionada permanentemente; e na Europa, serão os ingleses que se incumbirão de dirigir a luta contra a ocupação francesa. Um general inglês, Beresford, seráo comandante supremo do exército português e o efetivo governador do Reino libertado em 1809."

E o Brasil entra assim definitivamente na nova etapa do seu desenvolvimento. 10

Perde Portugal o domínio da colônia, com a abertura dos portos e a concorrência estrangeira e, sobretudo, com a condição de economias reflexas (Brasil e Portugal), contrapartida do poderio econômico inglês.

Um tratado de comércio com a Inglaterra em 1810 vai favorecê-la com uma tarifa preferencial de $15 \%$, enquanto no decreto de abertura dos portos fixara-se um direito geral de importação para todas as nações de $24 \%$ ad valorem e Portugal tinha uma tarifa reduzida de $16 \%$ maior portanto que as do ingleses. 0 absurdo da situação prevalece até 1815 quando as taxas se equiparam. Entretanto, o poderio inglês, com sua indústria e marinha mercante, excluiria Portugal da concorrência. O Brasil pois gravita na órbita inglesa. 
Estava destinada a um final malogro a tentativa de desenvolvimento independente de Irineu Evangelista de Souza, Visconde de Mauá, que montou uma fundição, uma fábrica de máquinas e um estaleiro, construindo ainda no Rio de Janeiro indústrias têxteis, linhas telegráficas, e fundando um banco. A partir de 1860, o desenvolvimento da produção cafeeira levaria à falência as empresas de Mauá. O livre-cambismo era exigido pelos barões do café, interessados na venda de seus produtos no mercado externo.

"Essa nova experiência histórica, em sua plenitude (econômica, política, social e cultural), vai condicionar o aparecimento de uma ideologia dominante, a do racionalismo individualista e burguês, oriundo de forma geral, do iluminismo, mas trazendo conteúdos anteriores, próprios da Ibéria ou só de Portugal, desdobrando-se a seguir em várias correntes de idéias mais ou menos sectárias ou ecléticas, de vária procedência européia, principalmente da Inglaterra e da França" ${ }^{11}$

"Estão presentes no processo de independência, iniciado em 1808, pensamento de J. J. Rousseau no ardente radicalismo de Frei Caneca, o teórico da sociedade patriarcal e burguesa da região provincial nordestina; o sólido liberalismo moralizante de Antonio Feijó, marcado pelo kantismo; o utilitarismo benthamiano que se manifesta entre os deputados da Assembléia Constituinte, como Bernardo Pereira de Vasconcelos; e outras tendências mais'.12

Em José da Silva Lisboa, Visconde de Cayrú, as idéias inglesas renovadoras daquela época já se manifestavam como atualização da filosofia, economia política e Direito Mercantil.

11. Prado, Jr., Caio. História Econômica do Brasil, Sāo Paulo, Brasiliense, 1986, p. 128.

12. Pereira, Aloysio Ferraz. Op. cit. 
Na segunda metade do século XIX (já referida na experiência do Visconde de Mauá) as atividades produtivas se deslocariam do norte para o centrosul. A produção de café desenvolve-se e entram em decadência as culturas de canade-açucar, algodão e tabaco. A partir de 1860 a dependência do estrangeiro aumenta, ainda que o comércio exterior apresente superavits. Produzem-se intensamente gêneros destinados à exportação (sobretudo café) e crescem as importações. Reforça-se a estrutura tradicional da economia brasileira.

Neste período, a guerra do Paraguai apresenta o quadro claro da ação premeditada e sistemática do imperialismo industrial, conduzido pela Inglaterra. $\mathrm{O}$ plano anglo-europeu teria o apoio da monarquia e das oligarquias provinciais e urbanas do Brasil. O Paraguai, que representava o esforço de independência econômica latino-americana, seria liquidado na sua autodeterminação política, que termina com cruel genocídio, resultado de colonização cultural, quando à Inglaterra soma-se o apoio da França. ${ }^{13}$

A expansão do consumo de café e o monopólio da produção no Brasil ocultaram a "fraqueza orgânica" do Império e o seu papel de contraparte no sistema imperialista industrial europeu. Exportações compensam o volume das importações, mas emissões de papel inconversível aumentam, bem como os empréstimos externos para custear as despesas da guerra do Paraguai. ${ }^{14}$

\section{Id. Ibid.}

14. Chiavenatto, Júlio José. Genocídio Americano: A Guerra do Paraguai, São Paulo, Brasiliense, 1985, pp. 9, 132, 141, 149. Material com força documental probatória.

"Em 1840 o Paraguai é um pais sem analfabetos. Existiam naquele tempo, para uma pequena população de menos de quatrocentos mil habitantes, quatrocentos e trinta e duas escolas com vinte $\mathbf{e}$ quatro mil alunos. Esse dado, muito bom para época e para as circunstâncias do país, chega a ser magnifico. Mais significativo que isso, porém é que toda uma estrutura sócio-econōmica atendendo plenamente aos interesses populares está livre de burocratas, cortesãos e os parasilas do gênero: no Paraguai só existe trabalho genuinamente produtivo. Não há divida externa - algo absolutamente impensável dentro das normas de governo de El Supremo. O pais está pronto para o desenvolvimento, que só não é pleno pelas taxas que Buenos Aires cobra para permitir a saída de seus produtos" (p. 9).

"O já citado e bastante conhecido Washburn, com a responsabilidade de representar no Plata o governo dos Estados Unidos, cultivava um particular ódio ao Paraguai: 'Por sua torpeza e cegueira junto com outros pecados, o povo paraguaio merece o completo exterminio que o aguarda. $O$ mundo terá justo motivo para congratular-se quando não houver nele uma só pessoa que fale o endiabrado idioma guarani'" (p. 132).

"Mas, o grande criminoso dessa guerra é o Conde D'Eu, genro de Pedro Il, que a partir de 1869 substitui o Duque de Caxias no comando do exército. A crônica de sua viliania tem aspectos mais rudes e selvagens. Ele mandou fechar o velho hospital de Peribebuy, mantendo no seu interior os enfermos a maioria de velhos e crianças - e incendiá-lo. O hospital em chamas ficou cercado pelas tropas brasileiras que, cumprindo ordens desse louco príncipe louro, empurravam à ponta de baionetas para dentro das chamas os enfermos que milagrosamente tentavam sair da fogueira. Não se consegue 
jurídicas no Brasil

O trabalho escravo, tardiamente abolido, faria afluir as correntes imigratórias européias, que aumentam sobretudo no período que antecede à Primeira Grande Guerra. Se os imigrantes vão concorrer para o desenvolvimento agrário e industrial, também vão representar mudança cultural considerável com suas técnicas, seus costumes e reivindicações sociais.

Apesar desses fatores de progresso, a dívida externa cresce: em 1889 é de aproximadamente trinta milhões de libras, em 1910 quase noventa milhões e em 1930, 250 milhões. $^{15}$

As primeiras décadas da República ajustam a economia brasileira aos interesses do comércio internacional. O Brasil adapta-se ao seu papel de semi-

na história da América do Sul, pelo menos, nenhum crime de guerra mais hediondo que esse. Incendiar um hospital e matar os enfermos! Queimar vivo velhos e crianças!

Pois as tropas aliadas, que cometeram tais crimes - os mais hediondos deles a mando do Conde $\mathrm{D}^{\prime} \mathrm{Eu}$, agiram por conta de governos que se esmeravam em apresentar ao mundo o Paraguai como o covil de bárbaros, a guerra como uma forma de redenção dos paraguaios das garras de Francisco Solano López! Nunca o crime de guerra andou tão intimamente ligado à calúnia, à infâmia e à mentira. Nunca se viu tanta vergonha na América" (p. 141).

"O genocídio está comelido: $75,75 \%$ do povo paraguaio estão mortos.

"99,50\% dos homens adultos foram mortos no Paraguai" (p. 149).

15. Furtado, Celso. Formação Econômica do Brasil, Rio de Janeiro, Editora Funđo de Cultura, 1961, pp. 210, 212,216, 217. Material necessário para exemplar prova histörica.

"A grande acumulação de estoques de 1929, a rápida liquidação das reservas metálicas brasileiras e as precárias perspectivas de financiamento das grandes safras previstas para o futuro aceleram a queda do preço internacional do café, iniciada conjuntamente com a de todos os produtos primários em fins de 1929.

Dadas as características da procura do café, cujo consumo não baixa durante as depressōes nos países de elevadas rendas, essa tremenda redução de preços teria sido inconcebível sem a situação especial que se havia criado do lado da oferta. Basta ter em conta que o preço médio pago pelo consumidor norte-americano, entre 1929 e 1931, baixou apenas de 47,9 para 32,8, centavos por libra. Acumularam-se, portanto, os efeitos de duas crises: uma do lado da procura e outra do lado da oferta. A situação favoreceu as organizações intermediárias no comércio do café, as quais percebendo a debilidada da posição da oferta puderam transferir para os produtores brasileiros a totalidade de suas perdas causadas pela crise geral" (p. 210).

"Dependendo, assim, fundamentalmente da estrutura da oferta, o preço do café atravessou o decênio dos anos trinta totalmente indiferente à recuperação que, a partir de 1934, se mantinha nos países industrializados. Após alcançar seu ponto mais baixo em alteração até 1937, para em seguida cair ainda mais nos dois últimos anos do decênio" (p. 212).

"É portanto, perfeitamente claro que a recuperação da economia brasileira, que se manifesta a partir de 1933, não se deve a nenhum fator externo e sim à política de fomento seguida inconscientemente no pais e que era um subproduto da defesa dos interesses cafeeiros. Consideremos o problema sob outro aspecto. A acumulação de estoques de café realizada antes da crise tinha a sua contrapartida em débitos contraídos no exterior. Não existia, portanto, nenhuma inversão líquida, pois que se invertia dentro do país, acumulando estoques, se desinvertia no exterior contraindo dívidas. Tudo ocorreria como se o café acumulado tivesse sido comprado por firmas estrangeiras que, no seu próprio interesse, postergavam o transporte da mercadoria para fora do país. A acumulação de café financiada do exterior se assemelha portanto a uma exportação" (pp. 216-217). 
colônia, que o professor Darcy Ribeiro chama de "atualização histórica" como expressão de um acomodar-se a uma situação que lhe é imposta de fora para dentro, em função de interesses que não são seus, mas que são assimilados por uma classe intermediária interessada na função serviçal.

A essa fase do capitalismo internacional, que se caracterizou pelos monopólios, pelo domínio do capital financeiro, pela exportação de capitais estrangeiros para as áreas periféricas, pela disputa de colônias e áreas de influências, é que se dá o nome de "imperialismo" Grandes capitais foram aplicados através de empréstimos aos governos latino-americanos, que pagavam altas taxas de juros. Sob esta nova situação criada pelo imperialismo, o Brasil teria que se recompor política, econômica e juridicamente.

"Já pouco antes da grande recessão iniciada em 1929, mas sobretudo a partir do início da segunda guerra mundial, o imperialismo econômico dos Estados Unidos da América se torna soberanamente hegemônico nos paises latino-americanos, entre os quais, naturalmente, o Brasil. $O$ aspecto dominante de sua penetração consiste no acaparamento de nossas principais e mais rendosas atividades econômicas, colocando-as na posição de simples elementos subsidiários dos grandes trustes e monopólios de âmbito internacional" 16

$\left.4^{\circ}\right)$ período do neo-colonialismo multinacional

Um quarto período pode ser acrescentado a esse panorama histórico e ideológico, com o neo-colonialismo multinacional, contraparte integrante da formação sócio-cultural do capitalismo industrial e monopolista; processo civilizatório comtemporâneo da revolução tecnológica industrial e consecutivo à revolução termo-nuclear: o século XX, a partir da década de 1940 . 